\title{
High-Flexion Total Knee Arthroplasty Using NexGen LPS-Flex System: Minimum 5-year Follow-up Results
}

\author{
Seung Joon Rhee, MD, Sung Min Hong, MD, and Jeung Tak Suh, MD \\ Department of Orthopaedic Surgery, Pusan National University Hospital, Busan, Korea
}

\begin{abstract}
Purpose: This study is to report clinical and radiological results of high-flexion total knee arthroplasty (TKA) using NexGen LPS-flex system at a minimum 5-year follow-up, and to analyze the implant survivorship based on the results.

Materials and Methods: A total of 80 patients (118 knees) who underwent patellar preserving TKA using NexGen LPS-flex implant between February 2007 and February 2008 and could be followed for minimum 5 years were reviewed. The range of motion (ROM), hip-knee-ankle angle, Knee Society Knee score (KSKS), and Knee Society Function score (KSFS) were assessed preoperatively and at the last follow-up and analyzed. Implant position of the femoral and tibial components on the immediate postoperative and last follow-up X-rays were compared.

Results: The mean ROM was $110.2^{\circ} \pm 14.5^{\circ}$ (range, $60^{\circ}$ to $140^{\circ}$ ) preoperatively and $132.4^{\circ} \pm 5.2^{\circ}$ (range, $90^{\circ}$ to $145^{\circ}$ ) at the last follow-up. KSKS was $36.9^{\circ} \pm 6.4^{\circ}$ preoperatively and $94.2^{\circ} \pm 3.2^{\circ}$ at the last follow-up. KSFS was $30.5^{\circ} \pm 5.7^{\circ}$ preoperatively and $93.7^{\circ} \pm 4.1^{\circ}$ at the last follow-up. There was no statistically significant change in the implant position measured as $\alpha, \beta, \gamma$, and $\delta$ angles at the last follow-up compared to the immediate postoperative values. Radiolucent lines were observed in 13 knees (11\%) on the last follow-up X-rays. Revision TKA was performed due to aseptic implant loosening in 1 knee $(0.84 \%)$, and the survival rate at the 5 th postoperative year was $99.2 \%$.

Conclusions: The clinical and radiological outcomes of high-flexion TKA using NexGen LPS-Flex implant design were satisfactory with 99.2\% implant survival rate after 5 years of protected activities of daily living.
\end{abstract}

Keywords: Knee, Arthroplasty, Prosthesis design, Survival analylsis

\section{Introduction}

Recovery of normal knee range of motion (ROM) is among the primary goals of total knee arthroplasty (TKA) since knee ROM is an important clinical indicator of knee joint function that can be used as a basis for the assessment of the success of TKA ${ }^{1-4)}$. Most daily living activities require $90^{\circ}-120^{\circ}$ knee $\mathrm{ROM}^{2,4)}$; however, kneeling, squatting, and sitting cross legged, which necessitate high flexion of the knee joint over $120^{\circ}$, are also required for

Received February 10, 2015; Revised April 19, 2015;

Accepted June 2, 2015

Correspondence to: Jeung Tak Suh, MD

Department of Orthopaedic Surgery, Pusan National University

Hospital, 179 Gudeok-ro, Seo-gu, Busan 49241, Korea

Tel: +82-51-240-7248, Fax: +82-51-247-8395

E-mail: jtsuh@pusan.ac.kr

This is an Open Access article distributed under the terms of the Creative Commons Attribution Non-Commercial License (http://creativecommons.org/licenses/by-nc/4.0/) which permits unrestricted non-commercial use, distribution, and reproduction in any medium, provided the original work is properly cited. daily living activities in some cultural, religious, or occupational environment ${ }^{2,3,5,6)}$. Among the various factors influencing postoperative knee joint ROM, implant design plays an important role, and the high-flexion TKA implant design was developed to enable more than $120^{\circ}$ postoperative flexion of the knee joint ${ }^{1-3,6-8)}$. Until recently, several manufacturers have introduced various designs of high-flexion TKA implants, and a number of researches regarding the difference between the conventional implant design and high-flexion implant design have been performed. However, the reality is there are as many studies reporting insignificant differences between the implant designs ${ }^{9-13)}$ as those reporting higher flexion after implantation of the high-flexion TKA designs ${ }^{14-17)}$. We compared the minimum 5-year follow-up results at our institution with the results of the previous papers. Although a number of studies reported good results of high-flexion TKA, few reports assessed the results after years of repetitive high-flexion. The purpose of this study is to analyze the survival rate of NexGen LPSFlex (Zimmer Inc., Warsaw, IN, USA) high-flexion implant at minimum 5-year follow-up based on radiological measurements 
and revision rates.

\section{Materials and Methods}

\section{Materials}

During the period from February 2007 to February 2008, a single surgeon operated TKA using NexGen LPS-Flex implant on 143 knees of 127 patients at our institution. Among them, 118 knees of 80 patients which could be followed for minimum 5 years (range, 5 to 7 years and 1 month; mean, 5 years and 9 months) were enrolled and their clinical and radiological data were analyzed. Patients with more than $15^{\circ}$ of preoperative varus alignment or more than $30^{\circ}$ of flexion contracture were excluded from the enrollment. There were 8 males ( 8 knees) and $72 \mathrm{fe}$ males (110 knees), and their age at the time of TKA was a mean of 67.4 years (range, 44 to 77 years). The indication for surgery was osteoarthritis in 73 patents (110 knees) and rheumatoid arthritis in 7 patients (8 knees). Unilateral surgery was done in 42 patients (42 knees) and staged bilateral surgery was done in 38 patients (76 knees) (Table 1 ).

\section{Surgical Techniques and Rehabilitation}

Midline skin incision and medial parapatellar approach were applied in all of the cases. Cruciate ligaments were resected as the implant design directs, and both the femoral and tibial components were fixed with bone cement. Bone cement was spread on the cut surface of the tibia and femur, and also on the implant itself. We cemented and implanted tibial implant first with 6-7 times off impaction using manufactured impactor and then removed excessive cement. After implantation of the tibial component was completed, the same routine was performed with the femoral implant. Just one mix of the cement was used for the

Table 1. Patient Demographics

\begin{tabular}{lc}
\hline \multicolumn{1}{c}{ Parameter } & Value (range) \\
\hline No. of patients & 80 \\
No. of knees & 118 \\
No. of bilateral TKA patients & 38 \\
Patient age (yr) & $67.4(44-77)$ \\
Proportion of males (\%) & 10 \\
Diagnosis (\%) & \\
$\quad$ Osteoarthritis & $110(99.2)$ \\
$\quad$ Rheumatoid arthritis & $8(0.8)$ \\
Follow-up (yr) & $5.75(5.00-7.08)$
\end{tabular}

TKA: total knee arthroplasty whole course of cementing. Then, the trial insert was inserted and maintained in position until the heat from the consolidating cement completely dissipated to secure balanced extension gap and to prevent the implant lift-off by the cement volume increment during the consolidation phase. Patellar resurfacing was not done in any case, but osteophyte removal and micro-drilling were done only in the cases with predictable poor patellofemoral tracking due to their severe degeneration.

Quadriceps muscle strengthening exercise was begun on the day of operation. Passive and active ROM exercises were begun on the 3rd postoperative day after the removal of drain. Full weight-bearing ambulation was permitted from the 1st postoperative week. Patients were encouraged to gain their maximum ROM until 2 to 3 months after TKA; however, we did not recommend squatting, kneeling, or sitting cross legged. Patients were instructed to avoid weight-bearing high-flexion activities as much as possible; however, they were encouraged to gain the ability to perform high-flexion.

\section{Clinical and Radiological Evaluation}

On clinical evaluation, Knee Society Knee score (KSKS) and Knee Society Function score (KSFS) assessed preoperatively and at the 5th postoperative year follow-up visit were compared. The roentgenographic evaluation and scoring system of the American Knee Society was used to measure and compare the preoperative radiography and postoperative 5-year radiography. Flexion angle of the knee joint was measured by comparing the angle between the longitudinal midline of the femur and tibia in full extension and full flexion positions on the sagittal plane radiograph. As for the change in the implant position, femoral component angle in coronal plane ( $\alpha$ angle), tibial component angle in coronal plane ( $\beta$ angle), femoral component angle in sagittal plane ( $\gamma$ angle), and tibial component angle in sagittal plane ( $\delta$ angle) were measured radiographically. Changes in the $\alpha, \beta, \gamma$, and $\delta$ angles between the immediate postoperative and 5-year postoperative follow-up were assessed. Bone-cement interface was set to 7 zones in coronal plane view of the femoral component and another 7 zones in coronal plane view of the tibial component, and 3 zones in sagittal plane. Thickness of radiolucent lines in $0.5 \mathrm{~mm}$ increments were measured in each zone. The sum of the scores in all of the zones was regarded as insignificant if it was less than 5 and highly suspicious of failure if the score was over 9 regardless of clinical symptoms. Scores between 5 and 9 were regarded as an indication for serial follow-up as to the progression of implant loosening. Gross displacement or tilting of the implant was regarded as implant fixation failure regardless of the presence of a radiolucent line. 


\section{Survival Analysis}

Kaplan-Meier survival analysis was done based on the 1-year follow-up results. The 1-year maintenance of the implant in its original location and in positions suggesting possibly good maintenance of the implant for a longer period was defined as annual success. Patient who were in their 5th postoperative year followup period were not included in this analysis, and deaths due to diseases or follow-up loss cases were excluded. Implant removal, revision, or infection was defined as failure.

\section{Statistical Analysis}

Independent t-test was performed to compare clinical and radiological results of preoperative and last follow-up assessments using SPSS ver. 18.0 (SPSS Inc., Chicago, IL, USA). Calculation of survival rates and standard deviations was also done using SPSS ver. 18.0. Log-rank test was used to determine the relationship between the survival rate and gender and causative diseases.

\section{Results}

\section{Clinical Results}

The mean knee flexion angle increased from a mean of $110.2^{\circ} \pm 14.5^{\circ}$ (range, $60^{\circ}$ to $140^{\circ}$ ) preoperatively to a mean of $132.4^{\circ} \pm 5.2^{\circ}$ (range, $90^{\circ}$ to $145^{\circ}$ ) at the last follow-up. The mean knee flexion contracture decreased from $7.8^{\circ}$ (range, $0^{\circ}$ to $25^{\circ}$ ) preoperatively to $1.3^{\circ}$ (range, $0^{\circ}$ to $10^{\circ}$ ) at the last follow-up. The KSKS increased from a mean of $36.9 \pm 6.4$ preoperatively to a mean of $94.2 \pm 3.2$ at the last follow-up. The KSFS increased from a mean of $30.5 \pm 5.7$ preoperatively to a mean of $93.7 \pm 4.12$ at the last follow-up (Table 2). Most patients were satisfied with the improvement in pain: 68 patients ( 100 knees, $85 \%$ ) out of 80 patients reported no pain or intermittent slight pain at the last follow-up visit.

Table 2. Changes in the ROM, HKAA, KSKS, and KSFS between the Preoperative and Last Follow-up Assessments

\begin{tabular}{lcccc}
\hline Variable & Preoperative & Last follow-up & Mean gain & p-value \\
\hline ROM $\left({ }^{\circ}\right)$ & $110.2 \pm 14.5$ & $132.4 \pm 5.2$ & 52.2 & 0.015 \\
HKAA $\left(^{\circ}\right)$ & $10.2 \pm 2.8$ & $-3.2 \pm 0.6$ & -13 & 0.002 \\
KSKS & $36.9 \pm 6.4$ & $94.2 \pm 3.2$ & 57.3 & 0.023 \\
KSFS & $30.5 \pm 5.7$ & $93.7 \pm 4.1$ & 63.2 & 0.011 \\
\hline
\end{tabular}

Values are presented as mean \pm standard deviation.

ROM: range of motion, HKAA: hip-knee-ankle angle, KSKS: Knee Society Knee score, KSFS: Knee Society Function score.

\section{Radiological Results}

Mechanical axis of the lower limb changed from a mean of $10.2^{\circ} \pm 2.8^{\circ}$ varus (range, $23^{\circ}$ varus to $7^{\circ}$ valgus) preoperatively to a mean of $3.2^{\circ} \pm 0.6^{\circ}$ valgus (range, $4^{\circ}$ varus to $7^{\circ}$ valgus) postoperatively. As for the implant position, the mean values of $\alpha, \beta, \gamma$, and $\delta$ angles were $96.2^{\circ} \pm 1.5^{\circ}$ (range, $94^{\circ}$ to $99^{\circ}$ ), $92.4^{\circ} \pm 1.1^{\circ}$ (range, $88^{\circ}$ to $94^{\circ}$ ), $3.2^{\circ} \pm 1.2^{\circ}$ (range, $0^{\circ}$ to $5^{\circ}$ ), and $85.6^{\circ} \pm 2.4^{\circ}$ (range, $80^{\circ}$ to $\left.90^{\circ}\right)$, respectively, immediately after surgery and $95.7^{\circ} \pm 1.7^{\circ}$ (range, $93^{\circ}$ to $98^{\circ}$ ), $92.9^{\circ} \pm 1.9^{\circ}$ (range, $89^{\circ}$ to $96^{\circ}$ ), $3.2^{\circ} \pm 1.2^{\circ}$ (range, $0^{\circ}$ to $5^{\circ}$ ), and $85.6^{\circ} \pm 2.4^{\circ}$ (range, $80^{\circ}$ to $90^{\circ}$ ), respectively, at the last follow-up. There was no significant change in the position and alignment of implant between the immediate postoperative and last follow-up measurements (Table 3). Radiolucent lines were observed in 13 knees (11\%) out of 118 knees during the 5-year follow-up. All of the radiolucent lines were in the femoral component: 4 were in zone 1 (anterior surface) and 9 were in zone 4 (posterior surface) (Figs. 1 and 2). The mean score of radiolucent lines in the femoral component was 0.5 (Table 4). However, there

Table 3. Changes of Component Alignment Angle between the Preoperative and Last Follow-up Assessments

\begin{tabular}{cccc}
\hline Angle & Preoperative $\left({ }^{\circ}\right)$ & Last follow-up $\left({ }^{\circ}\right)$ & p-value \\
\hline$\alpha$ angle & $96.2 \pm 1.5$ & $95.7 \pm 1.7$ & 0.861 \\
$\beta$ angle & $92.4 \pm 1.1$ & $92.9 \pm 1.9$ & 0.332 \\
$\gamma$ angle & $3.2 \pm 0.3$ & $3.2 \pm 1.2$ & 0.457 \\
$\delta$ angle & $85.3 \pm 1.9$ & $85.6 \pm 2.4$ & 0.182 \\
\hline
\end{tabular}

Values are presented as mean \pm standard deviation.

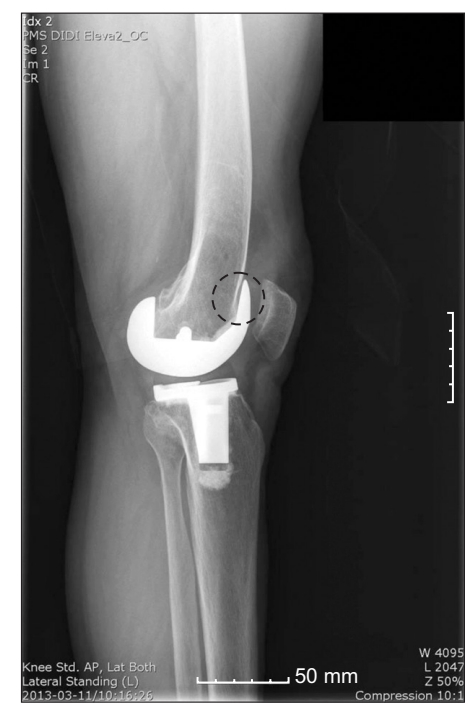

Fig. 1. Follow-up roentgenogram of a 65-year-old female patient showing a radiolucent line between the anterior flange of the femur and the femoral implant (zone 1). 


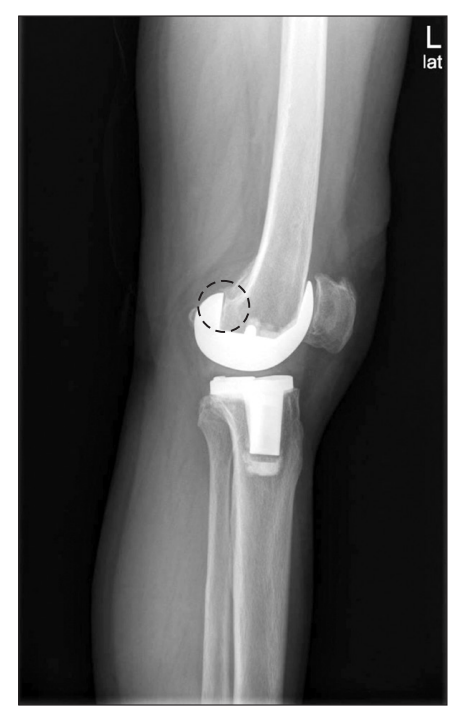

Fig. 2. Follow-up roentgenogram of a 70-year-old female patient showing a radiolucent line between the posterior cut surface of the femur and the posterior condyle of the femoral implant (zone 4).

Table 4. Incidence and Zone of Radiolucency

\begin{tabular}{lccc}
\hline \multicolumn{1}{c}{ Parameter } & $\begin{array}{c}\text { Incidence } \\
(\%)\end{array}$ & Score & $\begin{array}{c}\text { Zone of radiolucency } \\
\text { (cases) }\end{array}$ \\
\hline Femoral component & $13(11)$ & 0.5 & $1(4), 4(9)$ \\
Tibial component & 0 & & \\
\hline
\end{tabular}

was no statistically significant relationship between the existence of radiolucent lines and postoperative ROM ( $\mathrm{p}=0.901)$ and KSKS $(\mathrm{p}=0.321)$.

\section{Survival Analysis}

Removal of the implant due to loosening or revision operation was done in 1 knee (0.84\%). The overall survival rate calculated using the Kaplan-Meier method was 99.2\% (Fig. 3), and there was no statistically significant relationship between the survival rate and the gender $(\mathrm{p}=0.121)$ and causative diseases $(\mathrm{p}=0.257)$.

\section{Complications}

There were 2 cases of delayed wound healing and 1 case of revision due to aseptic loosening of the implant (Fig. 4). The 2 knees with delayed wound healing had past history of diabetes mellitus and their wounds were healed 3 weeks after the operation. Aseptic loosening occurred in the femoral component in the patient who had rheumatoid arthritis.

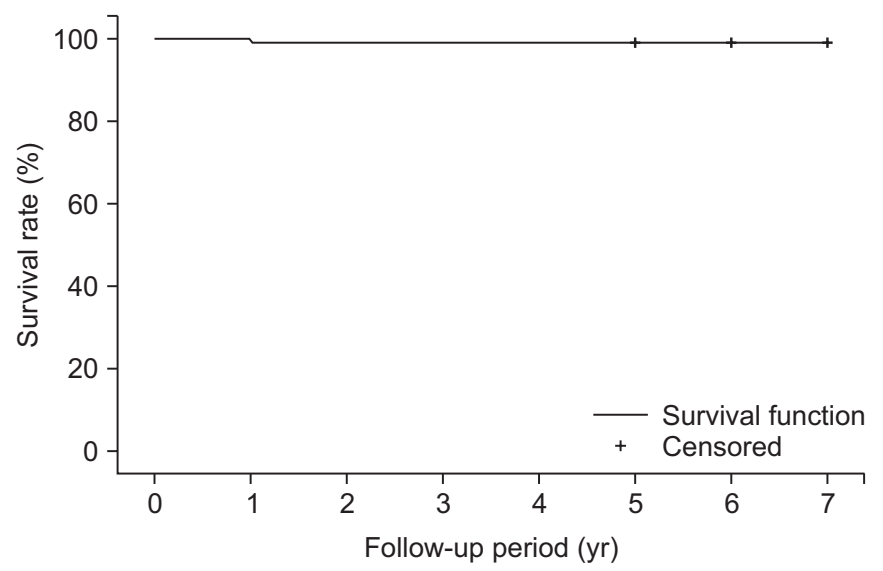

Fig. 3. Kaplan-Meier survival analysis: $99.2 \%$ survival rate at 5 years after surgery.

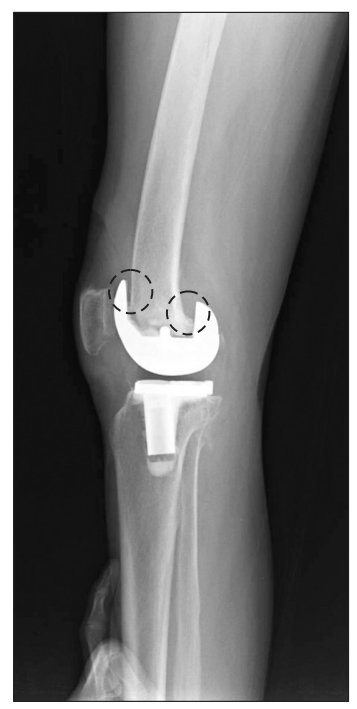

Fig. 4. A 74-year-old female patient was diagnosed with aseptic loosening and eventually underwent revision.

\section{Discussion}

Recently, vigorous research efforts have been made on implant designs, especially high-flexion designs, due to the increasing number of TKA even among young patients and the growing expectation on functional outcomes based on the improvement of implant durability. High-flexion after TKA is generally defined as greater than $125^{\circ}$ of knee joint flexion ${ }^{18}$. Compared with the conventional implant designs that allow maximum $120^{\circ}$ knee flexion, high-flexion designs theoretically enable more than $135^{\circ}$ knee joint flexion. Although the preoperative knee joint ROM is among the most important factors influencing high-flexion after $\mathrm{TKA}^{19)}$, maximum flexion angle could only be achieved with the 
aid of an improved implant design.

There are several design characteristics of high-flexion implant designs for improved dynamic conditions compared to the conventional designs ${ }^{20)}$. Increased posterior condylar offset makes the posterior condylar curve similar to the round shape, which enables femoral rollback in the higher flexion angle without impinging of the tibial component ${ }^{16,21,22)}$. Trochlear groove of the implant is elongated to avoid patella being entrapped in the intercondylar space with the longer distal contact surface of the patella and femoral components under the high-flexion circumstances. Anterior lip of the tibial polyethylene insert is beveled to avoid irritating patella and patellar tendon in the high-flexion state. Cam-post mechanism is also modified to increase the jump distance while preventing implant dislocation. Such changes in the implant design necessitate several changes in the surgical techniques as well. For example, $2-3 \mathrm{~mm}$ more resection of the posterior condyle is required to insert an implant with greater posterior offset. Sufficient exposure of the posterior joint capsule enhances removal of the posterior osteophytes impinging during high-flexion and enables concise balancing of the flexion gap ${ }^{21)}$. Meticulous resection of the tissues in the intercondylar space must be done for the well-operating high cam-post mechanism. Individualized implantation of a tibial component with a proper posterior slope and slightly posterior placement of the component to prevent flexion limitation caused by anterior sloping or anterior positioning of the tibial component are also required. Joint line elevation should be minimized to avoid patellar baja, which causes flexion limitation ${ }^{23)}$. On the other hand, it is also true that there are studies reporting increased chances of aseptic loosening, polyethylene insert wear, patellar insufficiency, and instability related to the characteristics of high-flexion implant designs ${ }^{3,5,6,24)}$.

During our research on the NexGen LPS-Flex single implant design, we could find 9 previous literatures regarding the same implant design ${ }^{5,8,12,13,15,24-30)}$ (Table 5). However, only 3 studies followed a relatively large group of more than 100 cases, and only 2 reports were based on more than 5-year follow-up. There was only 1 report which followed over 100 cases for more than 5 years. Under such circumstances, our minimum 5-year follow-up research on 118 knees with the NexGen LPS-Flex high-flexion implant design provides valuable and rare data. Our results showed a mean $22.2^{\circ}$ increase in the knee joint flexion angle from $110.2^{\circ} \pm 14.5^{\circ}$ (range, $60^{\circ}$ to $140^{\circ}$ ) preoperatively to $132.4^{\circ} \pm 5.2^{\circ}$ (range, $90^{\circ}$ to $145^{\circ}$ ) at the last follow-up, which was the highest flexion angle compared to that in the abovementioned researches, suggesting excellent improvement. KSKS was improved from $36.9 \pm 6.4$ preoperatively to $94.2 \pm 3.2$ at the last follow-up, and it was similar to the results of conventional literatures ranging from 76.9 to 97.6. In particular, in our study, radiological assessment on implant position and radiolucent lines was carried out to identify the presence of aseptic loosening and osteolysis. There was no significant change in the implant position from preoperative period to the last follow-up. Radiolucent lines were observed in 13 knees (11\%) and all of which were in the femoral component, but none of them met the criteria for implant failure. The existence of radiolucent lines showed no statistical correlation with

Table 5. Summary of Published Clinical Outcomes of Total Knee Arthroplasty Using the NexGen LPS-Flex Knee System

\begin{tabular}{|c|c|c|c|c|c|c|c|}
\hline \multirow{2}{*}{ Author } & \multirow{2}{*}{ No. of knees } & \multirow{2}{*}{ Follow-up (range) } & \multicolumn{2}{|c|}{$\mathrm{ROM}\left({ }^{\circ}\right)$} & \multicolumn{2}{|c|}{ Knee score } & \multirow{2}{*}{ Survivorship (\%) } \\
\hline & & & Preop & Postop & Preop & Postop & \\
\hline Cho et al. ${ }^{5)}$ & 218 & $3-6 \mathrm{yr}$ & 117.0 & 131.0 & 52.0 & 87.0 & 96.8 \\
\hline Lee et al. ${ }^{8)}$ & 41 & $2 \mathrm{yr}$ & 95.0 & 131.0 & & & 100 \\
\hline Malik et al. ${ }^{10)}$ & 90 & $1 \mathrm{yr}$ & 123.3 & 129.8 & & & \\
\hline Lee et $\mathrm{al}^{16)}$ & 35 & $35 \mathrm{mo}$ & 104.0 & 106.0 & & & \\
\hline Weeden and Schmidt ${ }^{17)}$ & 28 & $1 \mathrm{yr}$ & 108.0 & 110.0 & 50.7 & 76.9 & \\
\hline Han et al. ${ }^{24)}$ & 72 & $32 \mathrm{mo}(30-48)$ & 134.0 & 136.0 & & & 79.2 \\
\hline Han et al. ${ }^{25)}$ & 94 & $2 \mathrm{yr}$ & 128.4 & 132.7 & 53.7 & 97.6 & 100 \\
\hline Kim et $\mathrm{al}^{26)}$ & 100 & $10.3 \mathrm{yr}(10-10.6)$ & 125.0 & 135.0 & 28.0 & 92.0 & 99 \\
\hline Lionberger et al. ${ }^{27)}$ & 11 & $1 \mathrm{yr}$ & 113.5 & 124.0 & & & \\
\hline Singh et al. ${ }^{28)}$ & 100 & $2.1 \mathrm{yr}(1.6-2.5)$ & 112.0 & 123.0 & 38.7 & 79.9 & 100 \\
\hline Wohlrab et al. ${ }^{29)}$ & 30 & $65.7 \pm 5.2 \mathrm{mo}$ & 108.5 & 116.7 & & & 96.7 \\
\hline Yagishita et al. ${ }^{30)}$ & 29 & $5 \pm 0.7 \mathrm{yr}$ & 137.4 & 129.7 & 48.6 & 93.7 & 100 \\
\hline
\end{tabular}

ROM: range of motion, Preop: preoperative, Postop: postoperative. 
ROM or KSKS. In addition, the patients who showed radiolucent lines in the follow-up radiography reported they could perform more squatting and kneeling during daily living activities than they were recommended to do. Compared to the study of Han et al. ${ }^{24)}$, which reports high incidence of radiolucent lines (38\%) and revision surgery $(21 \%)$ at a mean of 23-month follow-up in the patients with the same NexGen LPS-Flex implant, our results showed $11 \%$ incidence of radiolucent lines and revision surgery was required in 1 knee due to aseptic loosening. Han et al. ${ }^{24)}$ allowed patients to do weight-bearing high flexion activities as tolerated. On the contrary, we advised patients not to squat or kneel while encouraging them to recover the ability to squat and kneel. We suspect that the postoperative patient education and activity restriction could have a profound influence on the difference of the study results. As for the survival analysis, there are literatures calculating survival rates merely based on the ratio of the total number of cases to the number of revision surgery, ignoring the timing of revision surgery or the influence of drop-outs during the research period. In contrast, the $99.2 \%$ survival rate in our study was calculated from the Kaplan-Meier survival analysis factoring in the influence of drop-out cases as well.

Until recently, numerous research and a few meta-analysis studies have been carried out regarding TKA implants. However, it is difficult to draw a convincing conclusion from a simple comparative study of the results due to the diverse operative techniques of individual surgeons and differences in the measurement methodology. The limitation of our study lies in the fact that it is not a comparative study, simply providing clinical results and the midterm survival rate of a single implant design. Therefore, we believe it is necessary to conduct a long-term comparative study on the conventional implant design vs. high-flexion design to analyze practical influence on the results of TKA in future research.

\section{Conclusions}

High-flexion TKA using NexGen LPS-Flex implant design yielded satisfactory clinical and radiological outcomes with $99.2 \%$ implant survival rate after 5 years of protected activities of daily living.

\section{Conflict of Interest}

No potential conflict of interest relevant to this article was reported.

\section{References}

1. Anouchi YS, McShane M, Kelly F Jr, Elting J, Stiehl J. Range of motion in total knee replacement. Clin Orthop Relat Res. 1996;(331):87-92.

2. Endres S. High-flexion versus conventional total knee arthroplasty: a 5-year study. J Orthop Surg (Hong Kong). 2011; 19:226-9.

3. Huddleston JI, Scarborough DM, Goldvasser D, Freiberg AA, Malchau H. 2009 Marshall Urist Young Investigator Award: how often do patients with high-flex total knee arthroplasty use high flexion? Clin Orthop Relat Res. 2009; 467:1898-906.

4. Miner AL, Lingard EA, Wright EA, Sledge CB, Katz JN; Kinemax Outcomes Group. Knee range of motion after total knee arthroplasty: how important is this as an outcome measure? J Arthroplasty. 2003;18:286-94.

5. Cho SD, Youm YS, Park KB. Three- to six-year follow-up results after high-flexion total knee arthroplasty: can we allow passive deep knee bending? Knee Surg Sports Traumatol Arthrosc. 2011;19:899-903.

6. Moon YW, Seo JG, Chang MJ, Yang JH, Jang SW. Minimum five-year follow-up results of single-radius, high-flex posterior-stabilized TKA. Orthopedics. 2010;33.

7. Bauman RD, Johnson DR, Menge TJ, Kim RH, Dennis DA. Can a high-flexion total knee arthroplasty relieve pain and restore function without premature failure? Clin Orthop Relat Res. 2012;470:150-8.

8. Lee BS, Kim JM, Lee SJ, Jung KH, Lee DH, Cha EJ, Bin SI. High-flexion total knee arthroplasty improves flexion of stiff knees. Knee Surg Sports Traumatol Arthrosc. 2011;19:936-42.

9. Kim YH, Sohn KS, Kim JS. Range of motion of standard and high-flexion posterior stabilized total knee prostheses: a prospective, randomized study. J Bone Joint Surg Am. 2005; 87:1470-5.

10. Malik A, Salas A, Ben Ari J, Ma Y, Gonzalez Della Valle A. Range of motion and function are similar in patients undergoing TKA with posterior stabilised and high-flexion inserts. Int Orthop. 2010;34:965-72.

11. McCalden RW, MacDonald SJ, Bourne RB, Marr JT. A randomized controlled trial comparing "high-flex" vs "standard" posterior cruciate substituting polyethylene tibial inserts in total knee arthroplasty. J Arthroplasty. 2009;24(6 Suppl):33-8.

12. Ng FY, Wong HL, Yau WP, Chiu KY, Tang WM. Comparison of range of motion after standard and high-flexion posterior 
stabilised total knee replacement. Int Orthop. 2008;32:795-8.

13. Nutton RW, van der Linden ML, Rowe PJ, Gaston P, Wade FA. A prospective randomised double-blind study of functional outcome and range of flexion following total knee replacement with the NexGen standard and high flexion components. J Bone Joint Surg Br. 2008;90:37-42.

14. Argenson JN, Komistek RD, Mahfouz M, Walker SA, Aubaniac JM, Dennis DA. A high flexion total knee arthroplasty design replicates healthy knee motion. Clin Orthop Relat Res. 2004;(428):174-9.

15. Bin SI, Nam TS. Early results of high-flex total knee arthroplasty: comparison study at 1 year after surgery. Knee Surg Sports Traumatol Arthrosc. 2007;15:350-5.

16. Li G, Most E, Sultan PG, Schule S, Zayontz S, Park SE, Rubash HE. Knee kinematics with a high-flexion posterior stabilized total knee prosthesis: an in vitro robotic experimental investigation. J Bone Joint Surg Am. 2004;86:1721-9.

17. Weeden SH, Schmidt R. A randomized, prospective study of primary total knee components designed for increased flexion. J Arthroplasty. 2007;22:349-52.

18. Long WJ, Scuderi GR. High-flexion total knee arthroplasty. J Arthroplasty. 2008;23(7 Suppl):6-10.

19. Ritter MA, Harty LD, Davis KE, Meding JB, Berend ME. Predicting range of motion after total knee arthroplasty. Clustering, log-linear regression, and regression tree analysis. J Bone Joint Surg Am. 2003;85:1278-85.

20. Argenson JN, Scuderi GR, Komistek RD, Scott WN, Kelly MA, Aubaniac JM. In vivo kinematic evaluation and design considerations related to high flexion in total knee arthroplasty. J Biomech. 2005;38:277-84.

21. Goldstein WM, Raab DJ, Gleason TF, Branson JJ, Berland K. Why posterior cruciate-retaining and substituting total knee replacements have similar ranges of motion. The importance of posterior condylar offset and cleanout of posterior condylar space. J Bone Joint Surg Am. 2006;88 Suppl 4:182-8.
22. Massin P, Gournay A. Optimization of the posterior condylar offset, tibial slope, and condylar roll-back in total knee arthroplasty. J Arthroplasty. 2006;21:889-96.

23. Figgie HE 3rd, Goldberg VM, Heiple KG, Moller HS 3rd, Gordon NH. The influence of tibial-patellofemoral location on function of the knee in patients with the posterior stabilized condylar knee prosthesis. J Bone Joint Surg Am. 1986; 68:1035-40.

24. Han HS, Kang SB, Yoon KS. High incidence of loosening of the femoral component in legacy posterior stabilised-flex total knee replacement. J Bone Joint Surg Br. 2007;89:1457-61.

25. Han CW, Yang IH, Lee WS, Park KK, Han CD. Evaluation of postoperative range of motion and functional outcomes after cruciate-retaining and posterior-stabilized high-flexion total knee arthroplasty. Yonsei Med J. 2012;53:794-800.

26. Kim YH, Park JW, Kim JS. High-flexion total knee arthroplasty: survivorship and prevalence of osteolysis: results after a minimum of ten years of follow-up. J Bone Joint Surg Am. 2012;94:1378-84.

27. Lionberger DR, Eggers MD, Brewer KE, Fang L. Improved knee flexion following high-flexion total knee arthroplasty. J Orthop Surg Res. 2012;7:22.

28. Singh H, Mittal V, Nadkarni B, Agarwal S, Gulati D. Genderspecific high-flexion knee prosthesis in Indian women: a prospective randomised study. J Orthop Surg (Hong Kong). 2012;20:153-6.

29. Wohlrab D, Hube R, Zeh A, Hein W. Clinical and radiological results of high flex total knee arthroplasty: a 5 year follow-up. Arch Orthop Trauma Surg. 2009;129:21-4.

30. Yagishita K, Muneta T, Ju YJ, Morito T, Yamazaki J, Sekiya I. High-flex posterior cruciate-retaining vs posterior cruciatesubstituting designs in simultaneous bilateral total knee arthroplasty: a prospective, randomized study. J Arthroplasty. 2012;27:36. 